\title{
A bitter pill
}

\section{Cuts in pharmaceutical $R \& D$ jobs might provide short-term improvements to the bottom line, but do not bode well for the industry in the long run.}

Right now does not seem to be a good time to be a pharmaceutical researcher. From the end of January through to February this year some of the world's biggest pharmaceutical companies seemed to be competing to see who could lay off the most staff. Such large and repeated cuts now seem to be a risk you face if you work in the industry, and empty promises from company management that these are the last cuts surely do little for the morale of the employees that remain.

The background to all of this is the low numbers of compounds that the companies have in their pipelines and the soon-to-expire patents of their highest selling drugs. The drug companies' response has been the same for several years - merge and try to make cost savings ${ }^{1}$. Having witnessed the repeated acquisitions and mergers of the recent past, cynics could be forgiven for suggesting that the goal is to become 'too big to fail'. In the short-term this works well for the profitability and share price, but drug discovery is a longterm business. It seems unlikely that those at the head of these companies are unaware of these facts, but the improved bottom line means that shareholders and (due to their salary packages) the company directors stand to profit more from this short-term view than by ensuring the long-term health of the industry.

So where is the industry headed? Are we witnessing a wholesale restructuring of the way these companies perform research? For many years, the large pharma companies have been outsourcing parts of their R\&D2 . Perhaps now they'd like to outsource everything, but it's hard to believe that this is the solution to the underlying issue - after all, it is often the same scientists who used to work directly for big pharma who now work at (and run) the contract research organisations. There does seem to be less risk for employees of these organizations - the failure of one project doesn't prevent them landing a contract from elsewhere. However, from a purely economic standpoint, if everything is outsourced, then the price of outsourced work would surely rise, thus making it a less attractive option.

To maintain in-house research and still reduce costs, many companies have begun moving their operations to China and India. Smaller salaries and less regulation are an easy way to cut costs. It is thus no surprise that the only part of GSK neuroscience research to survive the cuts is the neurodegeneration area based in Shanghai. Another option has been to in-license drugs developed by smaller companies. The approach is popular - it removes much of the risk from the early stages of development - but does this mean that the big pharmaceutical companies will just become the equivalent of venture capitalists that provide investment when they see something attractive?

There seems to be a fundamental problem with either approach. Medicinal chemistry is rarely a major part of the curriculum in chemistry degree courses and the pharmaceutical companies have usually preferred to recruit those with synthetic chemistry prowess, then provide the necessary medicinal chemistry experience in-house. Big pharma has therefore been something of a training ground for those who move on to lead research at the smaller companies. Having experts within the company is absolutely necessary ${ }^{3}$ and taking part in ongoing research is a major part of that expertise. For evidence of the problems with in-licensing, one needs to look no further than the ongoing uncertainty over the GSK deal for Sirtris ${ }^{4}$.

Big pharma and small start-up companies might have very different criteria for taking a drug candidate into clinical trials. Individuals working in either type of company doubtless have an underlying desire to 'make a difference' by discovering a drug that is life-changing, but this doesn't change the economics. Clinical trials are a costly venture and big pharma must see a reasonable chance of positive results before proceeding. For start-ups simply reaching this stage might be enough to bring in the buyers. Thus, although results in the clinic are never guaranteed, small start-ups do have an incentive to push forward less-viable drug candidates.

There have been suggestions that a bigger problem exists - that the opportunities to identify blockbuster drugs will be fewer and further between and that developed drugs will have a smaller market. Pharmaceutical research has always been a high-risk, highreward business, but despite already investing a larger percentage of returns $s^{5}$ in $\mathrm{R} \& \mathrm{D}$ than many other technical ventures, it may be that the rewards will be reduced.

Whether this is a short-term lull in the industry, or whether it is a sign of things to come, it is important to consider what these vast numbers of trained chemists will now do. Governments worldwide repeat calls for more science graduates ${ }^{6}-$ and in many ways it's not the new graduates who have the problem. The typical pharma job advert seeks a $\mathrm{PhD}$ graduate with $0-5$ years of experience - so the really bad news is for those more experienced chemists who have just been laid off.

Jobs in the pharmaceutical industry used to be second-to-none in terms of desirability - with big pharma you had a reasonable salary package and if not a 'jobfor-life, then a career where you could move on within the industry. Working for smaller start-up companies is necessarily less stable as the layoff of pre-clinical R\&D staff ${ }^{7}$ is often used to release capital for clinical trial costs.

It would now seem to be a tough task to convince a potential graduate student that this industry is so attractive. Who would invest years of their life and a lot of money into gaining a graduate degree if it offered only five years of employment before forcing a complete career change? And, if the uncertainty in the pharmaceutical job market is here to stay, the salary packages (which are unlikely to get bigger in a flooded market) look much less attractive if one has to keep money aside for the lean times.

Only time will tell the final outcome of the current upheaval, but one thing is clear - there are plenty of unsolved medicinal problems and plenty of people who want to make a difference. Good luck to all concerned.

\footnotetext{
References

1. http://go.nature.com/1dU1Eu

2. http://go.nature.com/6SPkcv

3. http://go.nature.com/ztOxmQ

4. http://go.nature.com/OMsM6D

5. LaMattina, J. L. Drug Truths: Dispelling the Myths About Pharma R\&D (Wiley, 2009).

6. http://go.nature.com/byOvaa

7. http://go.nature.com/uY3dTQ
}

\section{Correction}

In the Editorial Nature Chemistry 2, 241; 2010, there was an error with the shortened URL for reference 8 ; the full web address is http://chemjobber.blogspot.com/2009/06/ beryl-benderlys-article-on-slate-wrong.html 